\title{
Prenatal effects of maternal caffeine intake and dietary high protein on mandibular development in fetal rats
}

\author{
BY PHILIP G. DRISCOLL ${ }^{1}$, FRED JOSEPH JR ${ }^{2}$ AND TETSUO NAKAMOTO ${ }^{*}$ \\ Laboratory of Perinatal Nutrition and Metabolism, Departments of ${ }^{1}$ Physiology and ${ }^{2}$ Pediatrics, \\ Louisiana State University Medical Center, New Orleans, La 70119, USA
}

(Received 23 January 1989 - Accepted 22 September 1989)

\begin{abstract}
The purpose of the present study was to determine the effects of caffeine on the mandibles of newborn rats whose dams were given a normal diet $(200 \mathrm{~g}$ protein $/ \mathrm{kg}$ diet) compared with those given a highprotein diet (400 $\mathrm{g}$ protein $/ \mathrm{kg}$ diet) during gestation. A total of twenty pregnant Sprague-Dawley rats were randomly divided into four groups of five each. Starting on day 7 of gestation, groups 1 and 2 were fed on control and high-protein diets respectively, and groups 3 and 4 were pair-fed with groups 1 and 2 respectively, but with caffeine added to their diets. The caffeine supplement was $20 \mathrm{mg} / \mathrm{kg}$ body-weight. At birth, pups were killed and various measurements of their mandibles were made. The mandibular weights, calcium contents, and alkaline $(E C$ 3.1.3.1) and acid $(E C$ 3 1 1.3.2) phosphatase activities of the group given the caffeine-supplemented control diet were significantly lower than those of the corresponding unsupplemented group. Alkaline and acid phosphatase activities, collagen synthesis and hydroxyproline contents of the caffeine-supplemented high-protein group were greater than those of the corresponding unsupplemented group, whereas $\mathrm{Ca}$ and protein contents of the caffeine-supplemented high-protein group were lower than those of the corresponding unsupplemented group. There were no significant differences in plasma caffeine levels for either dams or pups between the caffeine-supplemented control and high-protein groups. The effects of caffeine on the development of fetal mandibles are apparently modified by different levels of maternal dietary protein.
\end{abstract}

Caffeine: Mandibular development: Dietary protein: Rat

Caffeine is present in many everyday household items which are widely used in our society. For example, it is present in coffee, tea and many carbonated drinks, and over-the-counter drugs used for allergies and colds (Graham, 1978). Caffeine has been shown to produce palatal and limb defects in fetal rats and to have an effect on chondrogenesis in the limbs (Nishimura \& Nakai, 1960). It may also cause the release of catecholamines from maternal adrenal glands and fetal tissue. Catecholamines cause a disturbance in circulation and decrease blood supply to the uterine vessels which may affect the growing fetuses (Moriguchi \& Scott, 1986).

In spite of the concern about caffeine, the majority of women still consume coffee and various other caffeine-containing products during pregnancy (Graham, 1978). Women who drink more thian five cups of coffee daily are more likely to have premature labour, a small fetus for the gestational period and a high incidence of an impending abortion (Furuhashi et al. 1985).

Diets in the US are reported to be relatively high in protein. The amount of protein consumed by pregnant women surveyed was $1443 \%$ above the recommended daily allowance (Chopra et al. 1978). An excess of dietary protein with a moderate intake of calcium results in a hypercalciuria in humans (Kim \& Linksweiler, 1979). In animal studies, excess dietary protein with adequate $\mathrm{Ca}$ has shown no effects on bone metabolism in 
Table 1. Composition of diets $(/ \mathrm{kg})$

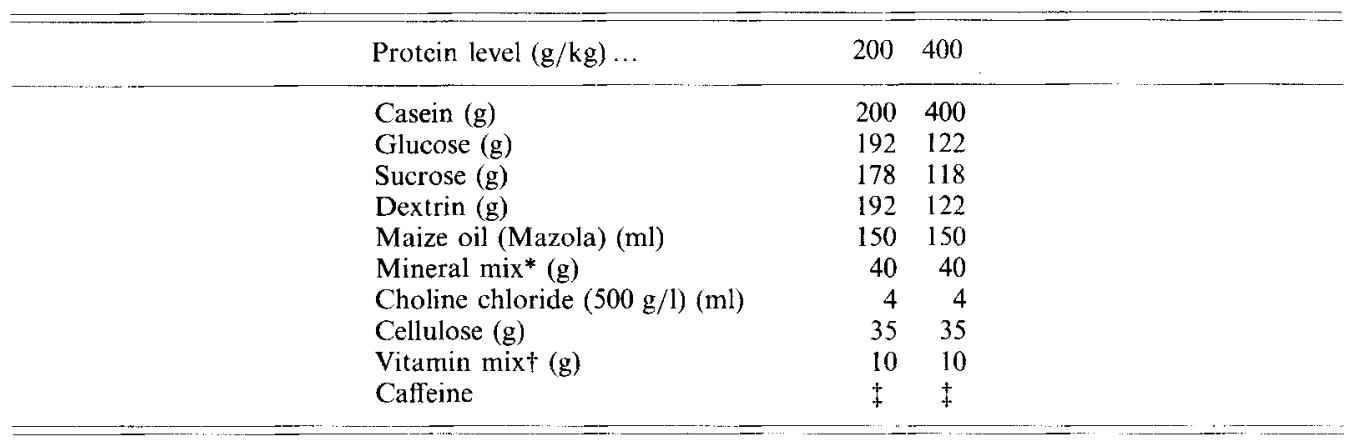

* Rogers-Harper Mineral Mix (Teklad Test Diets, Madison, WI).

$\uparrow$ AIN Vitamin Mixture 76 (ICN Pharmaceuticals Inc., Cleveland, OH).

\$20 mg/kg body-weight.

growing rats (Allen \& Hall, 1978) or adult mice (Yuen \& Draper, 1983). However, it is not clear at the present time to what extent, if any, the maternal high-protein diet with adequate $\mathrm{Ca}$ intake during the gestational period can influence bone development of the growing fetuses.

The present studies were conducted to determine whether or not the interaction between maternal high protein intake and caffeine supplementation would affect the development of the fetal bones. In addition, using high-performance liquid chromatography (HPLC), plasma caffeine levels in the dams and their pups were measured to investigate whether these levels might be altered by the nutritional status of the rats.

\section{MATERIALS AND METHODS}

A total of twenty timed-pregnant Sprague-Dawley rats were used (Holtzman Co., Madison, WI). Starting on day 7 of gestation, dams were fed on a specially prepared diet until the end of gestation. Twenty dams were randomly divided into four groups of five each. Dams of group 1 were fed ad lib. a control diet ( $200 \mathrm{~g}$ protein $/ \mathrm{kg}$ diet). Dams of group 2 were fed on a high-protein diet ( $400 \mathrm{~g}$ protein $/ \mathrm{kg}$ diet) ad lib. Group 3 was pair-fed to group 1 with a $200 \mathrm{~g}$ protein $/ \mathrm{kg}$ diet plus caffeine. Dams of group 4 were pair-fed to group 2 with a $400 \mathrm{~g}$ protein $/ \mathrm{kg}$ diet plus caffeine.

The diets were isoenergetic (Table 1); the increase in dietary protein content was made at the expense of carbohydrate. Caffeine was calculated to provide $20 \mathrm{mg} / \mathrm{kg}$ body-weight of dams. To determine the amount of caffeine necessary to provide a dietary content of $20 \mathrm{mg} / \mathrm{kg}$ body-weight in groups 3 and 4, average body-weights and daily food intakes of groups 1 and 2 were determined (Yazdani et al. 1987). The level of caffeine supplementation to the maternal diet was calculated by taking into account changes in the dams' bodyweights and their food intake. Because the dams' body-weights gradually increased during pregnancy, the amount of caffeine in the diets of the caffeine-supplemented groups was adjusted three times over the experimental period to maintain the designated intake. Theoretically the dams received slightly less caffeine toward the end of each given period when the level of caffeine supplementation was recalculated.

Dams were weighed every day, except at weekends. Within $8 \mathrm{~h}$ of birth, the pups in each groups were combined and weighed. There is no weight difference attributable to sex at an early age in rats (Nakamoto \& Miller, 1977). Three randomly selected pups from each 
group were then injected with uniformly labelled $\left[{ }^{14} \mathrm{C}\right]$ proline (specific activity $273 \mathrm{mCi}$ / mmol; New England Nuclear, Boston, MA) at a dose of $65 \mu \mathrm{Ci} / \mathrm{kg}$. They were then immediately returned on a random basis to a dam within the same group. $\left[{ }^{14} \mathrm{C}\right]$ prolineinjected pups were killed $6 \mathrm{~h}$ later, and blood samples were taken in order to determine the precursor pool of $\left[{ }^{14} \mathrm{C}\right]$ proline. The left and right mandibular bones of each pup were split with a sharp knife, skinned and removed. Tooth germs of molars and incisors and soft tissue were dissected out, together with mandibular nerves from the mandibular bodies, and discarded. The bones were then weighed, and collagen synthesis and total amount of collagen were determined. The procedures were described in detail recently (Nakamoto et al. 1987).

Other pups were randomly selected from each group. They were decapitated using scissors and blood was collected and pooled for the determination of plasma caffeine levels. Maternal blood was collected by cardiac puncture into heparinized tubes at the end of the experiment. Bone samples of these pups were removed as described previously. Cleaned mandibles were put in a muffle furnace overnight at $600^{\circ}$ and $\mathrm{Ca}$ content was measured by atomic absorption spectrophotometry (Nakamoto \& Miller, 1977).

Cleaned mandibles, in groups of six, were crushed in a well-chilled porcelain mortar with a porcelain pestle. They were subsequently homogenized in ice-chilled double-distilled water using a glass and Teflon homogenizing apparatus. After homogenization, samples were transferred to test-tubes. After standing for $15 \mathrm{~min}$ at $4^{\circ}$, the supernatant fraction was removed and used for protein and enzyme measurements. Total protein in the sample was assayed (Lowry et al. 1951). Alkaline (EC 3.1.3.1) and acid (EC 3.1.3.2) phosphatase activities were measured using a spectrophotometric method (Kuftinec \& Miller, 1972).

The caffeine content of plasma samples was measured as follows. Caffeine determinations were performed by HPLC using a Beckman model 344 gradient HPLC system with a $20 \mu \mathrm{l}$ sample loop and a model no. 427 integrator. The system contained a Supelco $\mathrm{C}_{18}$ precolumn and an Altex $46 \times 250 \mathrm{~mm}$ Ultrasphere ODS reverse-phase $\mathrm{C}_{18}$ column. The model 160 absorbance detector was set at a wavelength of $280 \mathrm{~nm}$ and run at 0.01 absorbance units full scale.

Samples were eluted over a 13 min time-period with a gradient of $100-400 \mathrm{ml}$ methanol/1 water at a flow-rate of $2 \mathrm{ml} / \mathrm{min}$. Three different levels of caffeine and an internal standard were used to calibrate the instrument. The internal standard, $\beta$-hydroxy-ethyl theophylline, and the caffeine standard were obtained from Sigma Chemical Co. (St Louis, MO). The methanol and water were HPLC grade.

Extraction was initiated by adding $200 \mu \mathrm{l}$ of each sample of rat plasma to $1 \mathrm{ml}$ absolute methanol, which precipitated protein. This contained $0.5 \mu \mathrm{g}$ of the internal standard. The extraction tubes were vortexed for $30 \mathrm{~s}$ and centrifuged at $4500 \mathrm{rev} . / \mathrm{min}$ for $10 \mathrm{~min}$. The supernatant fraction was subsequently transferred to $1.2 \times 75 \mathrm{~mm}$ tubes, and evaporated under nitrogen in a water-bath at $30^{\circ}$. The residue was prepared for injection by reconstituting in $200 \mu \mathrm{l}$ methanol $(100 \mathrm{ml} / 1$ water $)$.

All values were analysed using two-way analysis of variance and multiple comparison (Student-Newman-Keuls) using an Apple II microcomputer (Apple Corp., Cupertino, CA) with $P<0.05$ considered significant.

\section{RESULTS}

Average daily food intakes for the control (group 1) and high-protein (group 2) dietary group were 18 (SE 1) and 20 (SE 1) g respectively. Average food intakes for the caffeinesupplemented control (group 3) and high-protein (group 4) dietary groups were 17 (SE 1) and 20 (SE 1) g respectively. The average number of offspring in each group was as follows: 
Table 2. Caffeine contents $(\mu \mathrm{g} / \mathrm{ml})^{*}$ in plasma of dams and pups fed on caffeinesupplemented $(20 \mathrm{mg} / \mathrm{kg}$ body-weight) control $(200 \mathrm{~g}$ protein $/ \mathrm{kg})$ and high-protein $(400 \mathrm{~g}$ protein $/ \mathrm{kg}$ ) diets $†$

(Mean values with their standard errors)

\begin{tabular}{|c|c|c|}
\hline No. of measurements ... & $\begin{array}{c}\text { Maternal } \\
\text { plasma } \\
4\end{array}$ & $\begin{array}{c}\text { Pups' } \\
\text { plasmaß } \\
4\end{array}$ \\
\hline \multicolumn{3}{|c|}{$200 \mathrm{~g}$ protein $/ \mathrm{kg}$ diet plus caffeine } \\
\hline Mean & 3.089 & $2 \cdot 642$ \\
\hline SEM & 1.026 & $1 \cdot 040$ \\
\hline \multicolumn{3}{|c|}{$400 \mathrm{~g}$ protein $/ \mathrm{kg}$ diet plus caffeine } \\
\hline Mean & 1.310 & 1.111 \\
\hline SEM & 0.700 & 0.658 \\
\hline
\end{tabular}

\footnotetext{
* Pups' plasma for measurement of caffeine content was collected no later than $13 \mathrm{~h}$ after birth. Dam's plasma was collected no later than $16 \mathrm{~h}$ after delivery.

$\dagger$ For details, see Table 1 and p. 286.

Each dam's plasma was analysed for caffeine content.

$\S$ For each litter plasma from pups that had not been given an injection of $\left[{ }^{14} \mathrm{C}\right]$ proline was pooled to measure caffeine content.
}

group 1, 10 (SE 2); group 2, 10 (SE 1); group 3, 8 (SE 1); group 4, 9 (SE 1). There was no statistically significant difference in the number of fetuses among the groups.

The volume of blood plasma collected from one litter of both the caffeine-supplemented control and the high-protein dietary groups was insufficient to measure caffeine, so the caffeine levels of the respective dams were not determined. The mean plasma caffeine concentrations in both dams and pups in the caffeine-supplemented high-protein dietary group were lower than in the caffeine-supplemented control group, but, because of the very large variances, the differences were not statistically significant (Table 2).

There were no statistically significant differences in the birth weights of the groups, although there was a tendency for the high-protein diet groups to have higher body-weights and for caffeine to lower body-weights (Table 3). Mandibular weights, $\mathrm{Ca}$ contents and alkaline and acid phosphatase activities of the group fed on a caffeine-supplemented control diet were lower than those of the corresponding unsupplemented group. $\mathrm{Ca}$ and protein contents of the group fed on the caffeine-supplemented high-protein diet were lower than those of the corresponding unsupplemented group. On the other hand, alkaline and acid phosphatase activities, collagen synthesis and hydroxyproline contents of the group fed on the caffeine-supplemented high-protein diet were greater than those of the corresponding unsupplemented group (Table 3 ).

Alkaline and acid phosphatase activities of the group fed on the high-protein diet were lower than those of the control group, whereas the protein levels of the group fed on the high-protein diet were higher than those of the control group. Mandibular weights, alkaline and acid phosphatase activities and collagen synthesis of the group fed on the caffeinesupplemented high-protein diet were higher than those of the group fed on the caffeinesupplemented control diet (Table 3 ).

\section{DISCUSSION}

Assuming the average caffeine content of a cup of coffee to be $100 \mathrm{mg}$, the present level of caffeine supplementation of the maternal diet is equivalent to a daily intake of ten cups of coffee for a $50 \mathrm{~kg}$ female (Gilbert \& Pistey, 1973). 
CAFFEINE AND BONE

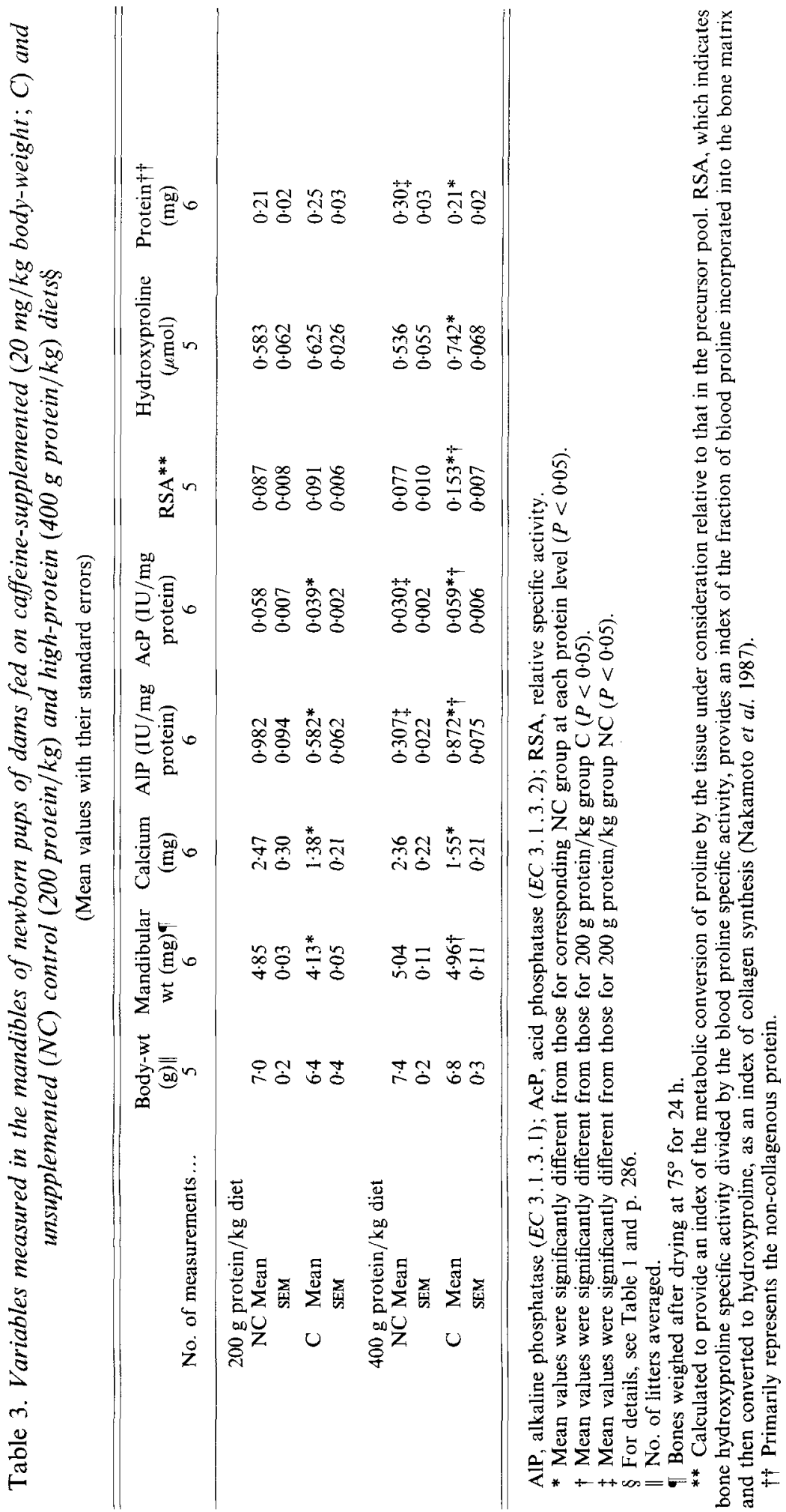


Graham (1978) reported that $74 \%$ of pregnant females consume caffeine, the mean daily intake being slightly more than two cups of coffee, which at the 99 th percentile is equivalent to eight cups of coffee. The increased consumption of soft drinks containing caffeine in the past 10 years suggests that the trend for caffeine intake by individuals must be upward, indicating a need to study the effects on the fetus of caffeine intake during pregnancy.

Caffeine and its metabolites pass freely into the embryo and attain concentrations slightly lower than those in the maternal plasma (Scott, 1983). Caffeine may also be poorly metabolized during pregnancy (Kline $\&$ Christensen, 1971), causing an accumulation in the fetal tissue (Henderson \& Schenker, 1984).

Plasma caffeine levels showed a wide range among the dams as well as among litters, as is shown by the large standard error of means. Although animals were killed at the same time of day, the high variability within dietary groups could partly be due to the food being eaten at different times. It could be argued that dams and pups should be fasted for a specified time period before blood plasma is collected, to obtain less variable caffeine levels. However, with fast-growing pups and lactating dams and the varying eating habits of individual dams, fasting could result in distortion in various measurements conducted on bones.

Because the mean plasma caffeine concentrations in the high-protein dietary group are so far below those of the control group (although not actually significantly different), further studies are warranted to determine the effects of dietary protein levels on metabolic processes controlling plasma caffeine levels.

The different effects observed in caffeine-supplemented and unsupplemented control and high-protein dietary groups for the variables measured suggest that the effects of caffeine may be modified by different nutritional conditions. It is well known that chemicals and drugs can interact with nutrients, including dietary protein levels (Kato et al. 1968; Newberne et al. 1978).

Alkaline phosphatase activity is reported to have a close functional association with calcification (Salomon, 1974) and bone growth (McWhinnie, 1975), whereas acid phosphatase activity is known to be related to bone resorption (Marks, 1974). We measured alkaline and acid phosphatase activities to determine whether differences in the activities of these enzymes can provide some indication of Ca content.

A decrease in the ratio of alkaline:acid phosphatase activities, for example, indicates a shift of balance towards resorption and thus a lowering of Ca content. Administration of caffeine lowered Ca content. Therefore, in theory, caffeine should lower the ratio of alkaline:acid phosphatase activity in the caffeine-supplemented group relative to the corresponding unsupplemented group. In the control group there was a decrease of $12 \%$, whereas in the high-protein dietary group the ratio was increased by $44 \%$.

The activity ratio of alkaline:acid phosphatase in the unsupplemented high-protein dietary group was about $60 \%$ of that of the unsupplemented control group. However, the total amount of calcium was about the same in these groups. Thus, the hypothesis that measurement of the ratio of alkaline:acid phosphatase activities can provide some indication of $\mathrm{Ca}$ content is not supported by the evidence in the present study.

The alkaline phosphatase activity of the metaphyses has been shown to be increased with a high-protein diet in young growing rats (Weiss et al. 1981). However, this enzyme was decreased with the high-protein diet in the present study. This discrepancy is not surprising due to the different experimental conditions and the different bones investigated in the present study as compared with those in the study of Weiss et al. (1981).

cAMP is reported to increase collagen synthesis in fetal calvaria (Phang \& Downing, 1973 ). Caffeine has been known to increase cAMP by inhibiting phosphodiesterase ( $E C$ 3.1.4 17) (Butcher \& Sutherland, 1962). Thus, it is conceivable that collagen synthesis and 
total hydroxyproline content, which reflect collagen levels (Bollet, 1970), were increased in the caffeine-supplemented high-protein group compared with the unsupplemented group.

Protein content, measured by an established method (Lowry et al. 1951), represents primarily non-collagenous protein. Although small amounts of collagen may also be included, this is negligible. Thus, increased hydroxyproline content and decreased protein content in the caffeine-supplemented high-protein group, compared with the unsupplemented group, indicates that the composition of the collagenous and non-collagenous portions of the organic matrix of the mandible differed between groups.

In a previous study (Nakamoto \& Shaye, 1986), we demonstrated that the effect of caffeine on the mandible of the fetus is altered by a maternal dietary protein deficiency. In the present study, it was demonstrated that a maternal dietary protein excess also interacts with caffeine intake and influences fetal mandibular development. While interspecies extrapolation from rat models to the human must be made with caution, pregnant women are nevertheless frequently exposed to caffeine. Thus, some consideration of the interactions between maternal caffeine intake and dietary protein levels during pregnancy could be important for healthy mandibular development in the fetus.

The authors wish to express sincere appreciation for the help provided by $\mathrm{Mr} \mathrm{J}$. Morris and Ms G. Young, as well as Mr R. Wolfe of the Editorial Office of the Louisiana State University Medical Center. This study was supported in part by BRSG SO7 RRO5704-15 DRR NIH.

\section{REFERENCES}

Allen, L. H. \& Hall, T. E. (1978). Calcium metabolism, intestinal calcium-binding protein and bone growth of rats fed high protein diets. Journal of Nutrition 108, 967-972.

Bollet, A. J. (1970). Effect of protein depletion on skin and bone collagen. Mount Sinai Journal of Medicine 38, 445-449.

Butcher, R. W. \& Sutherland, E. W. (1962). Adenosine 3',5'-phosphate in biological materials. Journal of Biological Chemistry 237, 1244-1250.

Chopra, J. G., Forbes, A. K. \& Habicht, J. P. (1978). Protein in the U.S. diet. Journal of the American Dietetic Association 72, 253-258.

Furuhashi, N., Sato, S., Suzuki, M., Hiruta, M., Tanaka, M.\& Takashashi, T. (1985). Effects of caffeine ingestion during pregnancy. Gynecologic and Obstetric Investigation 19, 187-191.

Gilbert, E. F. \& Pistey, W. R. (1973). Effect on the offspring of repeated caffeine administration to pregnant rats. Journal of Reproduction and Fertility 34, 495-499.

Graham, D. (1978). Caffeine - its identity, dietary course and biological effects. Nutrition Reviews 36, 97-102.

Henderson, G. L. \& Schenker, S. (1984). Effects of ethanol and/or caffeine on fetal development and placental amino acid uptake in rats. Developmental Pharmacology and Therapeutics 7, 177-187.

Kato, R., Oshima, T. \& Tomizawa, S. (1968). Toxicity and metabolism of drugs in relation to dietary protein. Japanase Journal of Pharmacology 18, 356-366.

Kim, Y.\& Linksweiler, H. M. (1979). Effect of level of protein-intake on calcium metabolism and on parathyroid and renal function in the adult human male. Journal of Nutrition 109, 1399-1404.

Kline, O. R. \& Christensen, H. D. (1971). Caffeine elimination in late pregnancy. Federation Proceedings $38,266$.

Kuftinec, M. M. \& Miller, S. A. (1972). Alkaline and acid phosphatase activities during growth of long bones and mandibles. Calcified Tissue Research 9, 173-178.

Lowry, O. H., Rosebrough, N. J., Farr, A. L. \& Randall, R. J. (1951). Protein measurement with the Folin phenol reagent. Journal of Biological Chemistry 193, 265-275.

McWhinnie, D. J. (1975). In vivo effects of mammalian thyrocalcitonin on bone growth and alkaline phosphatase activity in the chick embryo. Comparative Biochemistry and Physiology 50 A, 169-175.

Marks, S. C. (1974). A discrepancy between measurements of bone resorption in vivo and in vitro in newborn osteopetropic rats. American Journal of Anatomy 141, 329-343.

Moriguchi, M. \& Scott, W. J. Jr (1986). Prevention of caffeine-induced limb malformations by maternal adrenalectomy. Teratology 33, 319-322.

Nakamoto, T. \& Miller, S. A. (1977). Effects of protein-energy malnutrition on the growth of mandible and long bone in newborn male and female rats. Journal of Nutrition 197, 983-989. 
Nakamoto, T., Rothermel, K. S. \& McGrath, K. R. (1987). Biochemical and physical alterations of bones in newborn rats due to excess methionine administered either by gastric intubation or by maternal milk. Archives of Oral Biology 32, 101-105.

Nakamoto, T. \& Shaye, R. (1986). Protein-energy malnutrition in rats during pregnancy modifies the effects of caffeine on fetal bone. Journal of Nutrition 116, 633-640.

Newberne, P. M., Gross, R. L. \& Roe, D. A. (1978). Drug, toxin and nutrient interactions. World Review of Nutrition and Dietetics 29, $130-169$.

Nishimura, H. \& Nakai, K. (1960). Congenital malformations in offspring of mice treated with caffeine. Proceedings of the Society for Experimental Biology and Medicine 104, 140-145.

Phang, S. M. \& Downing, S. J. (1973). Amino acid transport in bone: stimulation by cyclic AMP. American Journal of Physiology 24, 191-196.

Salomon, C. D. (1974). A fine structural study on the extracellular activity of alkaline phosphatase and its role in calcification. Calcified Tissue Research 15, 201-212.

Scott, W. J. Jr (1983). Caffeine-induced limb malformations: Description of malformations and quantitation of placental transfer. Teratology 28, 427-435.

Weiss, R. E., Gorn, A., Durc, S. \& Nimni, M. E. (1981). Influence of high protein diet on cartilage and bone formation in rats. Journal of Nutrition 111, 804-816.

Yazdani, M., Tran, T. H., Conley, P. M., Laurent, J. Jr \& Nakamoto, T. (1987). Effect of protein malnutrition and maternal caffeine intake on the growth of fetal rat brain. Biology of the Neonate 52, 86 92 .

Yuen, D. E. \& Draper, H. H. (1983). Long-term effects of excess protein and phosphorus on bone homeostasis in adult mice. Journal of Nutrition 113, 1374-1380. 